\title{
Effect of Horse Riding on Balancing Ability in Children with Cerebral Palsy
}

\author{
Ok-Deuk Kang ${ }^{1 *}$, Min-Soo Kang ${ }^{1}$ and Anna Kang ${ }^{2}$ \\ ${ }^{1}$ Division of Biotechnology, Jeju National University, Jeju 690-756, South Korea, ${ }^{2}$ Physical Therapist, Notre Dame \\ Rehabilitation Center, Incheon, 407-052, South Korea
}

\begin{abstract}
This study was conducted to investigate the effect of a horse riding program on balancing ability in children with cerebral palsy. Eleven children (five males and six females) diagnosed with cerebral palsy participated. The horse riding exercises (walking and trotting) were conducted twice per week for 30 minutes during 24 weeks. Balancing ability was measured three times at pre, mid, and post-test using an air pad by the same physical therapist. The data were analyzed using a two-way repeated-measures analysis of covariance with time $(0,12$, and 24 weeks) using SPSS version 18.0. A comparison of horse riding between patients with hemiplegia and paraplegia was conducted with the Willcoxon signed-ranktest at a predetermined probability rate of $5 \%$. The results showed a significant increase in balancing ability after horse riding than that before horse riding $(\mathrm{p}<0.01)$. The average balancing score increased greater in males $(54.59 \pm 84.05)$ than that in females $(27.84 \pm 12.67)$ after the horse riding exercise program compared to that before the program $(\mathrm{p}<0.05)$. Thus, horse riding exercise was considered an effective to improve balance in children with cerebral palsy. These results provide useful basic data for horse riding for the disabled.
\end{abstract}

(Key words : Cerebral palsy, Equine assisted therapy, Rehabilitation, Horse riding)

\section{INTRODUCTION}

Cerebral palsy (CP) is caused by damage or lesions in the developing brain during pregnancy, childbirth, or after birth. $\mathrm{CP}$ is a clinical syndrome of non-progressive and noncontagious motor conditions that cause physical disability and difficulty controlling the body (Vargus-Adams, 2005; Barlow et al., 2007). CP is a chronic disease that requires life-long physical and occupational therapy and is a permanent disability accompanied by movement and posture disabilities as well as disturbances in sensation, behavior, and cognition (Ionatamishvili, 2004).

The common characteristics of patients with $\mathrm{CP}$ are that they cannot maintain proper posture and balance, because they have trouble controlling their head and stabilizing their trunk. Additionally, patients with $\mathrm{CP}$ have imbalanced muscle tone due to muscular weakness and atrophy from muscle stiffness. Therefore, patients with $\mathrm{CP}$ must maximize their potential by systematically and continuously strengthening their physical motor ability (Sherri et al., 2002; Dodd et al., 2003) to promote functional independency.

In particular, improving trunk balancing skill to relieve spasticity and improve walking ability is critical for patients with $\mathrm{CP}$, and a variety of therapies are available to strengthen trunk muscles (Kim, 2005; Lee, 2009). Horse riding for the disabled is a form of sports intervention therapy, which uses the characteristic movements of a horse and is widely used for patients with $\mathrm{CP}$, as it promotes postural stability and stimulates a sense of balance (Liptak, 2005).

After establishment of the Riding for the Disabled Association in 1969, many countries, including the US, have used horse riding as therapy for people with disabilities.

Strerba et al. (2002) reported an overall improvement in gross motor function measures after 18 weeks of horse riding Silkwood-Sherer (2007) found a significant improvement in balance after 7 weeks of horse riding, whereas Bergene (2006) showed an increased range of motion after 18 weeks of horse riding.

Riding has been used for children with $\mathrm{CP}$ in Korea, and its effectiveness has been demonstrated (Kim et al., 2005; Yong et al., 2010; Kwon et al., 2011). Kim et al. (2005) reported that children with $\mathrm{CP}$ show improved gross motor function after horse riding for 10 weeks, and Kwon et al. (2011) reported that 8 weeks of horse riding helped patients with $\mathrm{CP}$ improve their gross motor function and results on a

* Corresponding author: Ok-Deuk Kang, Division of Biotechnology, Jeju National University, 102 Jejudaehakno, Jejusi, Jejudo, 690-756, Korea. Tel: +82-64-727-3232, Fax: +82-64-725-7003, E-mail: kod0816@nate.com 
balance test for children. Yong et al. (2010) also reported that 5 months of horse riding therapy helped improve gross motor function.

We hypothesized that children with $\mathrm{CP}$ would show improved balance after completing a horse riding program.

Although horse riding has been used widely as therapy for children with $\mathrm{CP}$, studies on the effects of horse riding for the disabled are rare. Therefore, this study aimed to confirm the effectiveness of horse riding for the disabled and present fundamental data for therapy. Thus, a 6 month horse riding program was carried out for children with $\mathrm{CP}$ to improve their balancing ability.

\section{MATERIALS AND METHODS}

\section{Participants}

The participants consisted of 13 children with CP(five boys and eight girls). Six of the participants had hemiplegia and five had paraplegia. This study was conducted with disabled children who could participate in the horse riding program thus, children with epilepsy or convulsion were excluded. The parents of all participants signed consent for their children to participate in this program before conducting the study. Table 1 shows the detailed physical features of the participants.

\section{Experimental design}

The study was conducted in a rectangular riding area with two female horses a Jeju pony and a Shetland pony (age, $10.5 \pm 0.7 \mathrm{yr}$; height, $132.5 \pm 2.1 \mathrm{~cm}$ weight, $240 \pm 2.1 \mathrm{~kg}$ ). The horse riding exercise was carried out 30 minutes per day, twice a week for 24 weeks. Walking and trotting movements were used. Results were measured before starting the program, at 12 weeks, and at 24 weeks at the end of the program.

The horse riding program focused on teaching horse riding skills, not riding for the disabled, in which the horse was used as a tool. This approach was considered helpful for children with CP to keep their balance using stirrups, as the horse movement repeatedly requires sitting down and standing up (rising trotting). Although the rhythm of sitting down and standing up is a technique used in trotting, we used it during walking as well (approximately 10 minutes, which varied slightly depending on the participant). Additionally, the participants used a saddle with stirrups as a way to communicate with the horses to strengthen various muscles during horse riding. The exercise program was planned in three phases a warm-up for 5 minutes (stretching on the horse), horse riding for 20 minutes, and a 5 minute warmdown.

Leaders controlled the steps and speed of the horse with a leading rope and helped the riders feel a variety of horse movements. Assistants supported the riders based on their individual need. All participants wore a three-point helmet for their safety during horse riding and used a normal saddle.

\section{Method for measuring balancing ability}

Table 1. Characteristics of the participants

\begin{tabular}{ccccccc}
\hline Participants & Gender & Age & Weight $(\mathrm{kg})$ & Height $(\mathrm{cm})$ & Grade & Type \\
\hline \hline 1 & Boy & 10 & 19.1 & 114 & 1 & Hemiplegia (R) \\
2 & Boy & 10 & 27.3 & 110 & 1 & Hemiplegia (R) \\
3 & Boy & 10 & 27.2 & 110 & 3 & Paraplegia \\
4 & Boy & 7 & 14.8 & 102 & 2 & Paraplegia \\
5 & Boy & 13 & 25.9 & 112 & 3 & Hemiplegia (R) \\
6 & Girl & 11 & 21.0 & 112 & 2 & Hemiplegia (R) \\
7 & Girl & 9 & 20.8 & 110 & 3 & Paraplegia \\
8 & Girl & 12 & 24.0 & 109 & 1 & Paraplegia \\
9 & Girl & 11 & 25.7 & 116 & 2 & Paraplegia \\
10 & Girl & 7 & 16.9 & 103 & 1 & Hemiplegia (R) \\
11 & Girl & 8 & 14.2 & 106 & 1 & Hemiplegia (R) \\
Mean \pm SD & & $9.82 \pm 1.94$ & $21.54 \pm 4.85$ & $109.45 \pm 4.32$ & & \\
\hline
\end{tabular}


The instrument to measure balance was a circular air pad $(34.5 \mathrm{~cm}$ diameter $\times 5.5 \mathrm{~cm}$ tall). Participants stood on a circular air pad, and we measured the time they could balance. To minimize measurement error between contact points, one physical therapist obtained all of the measurements and selected the best value among three measurements obtained during each test.

\section{Statistical analysis}

Data processing was conducted with the SPSS version 18.0 statistical program (SPSS Inc., Chicago, IL, USA). Data were analyzed using a two-way repeated-measures analysis of covariance with time $(0,12$, and 24 weeks $)$. The comparison of the type of $\mathrm{CP}$ was made using the Wilcoxon signed-rank test. A p-value $<0.05$ was considered significant.

\section{RESULTS}

Children with CP participated in a 24 week horse riding program to determine its effect on balance. Table 2 shows the changes in balancing ability based on the duration of horse riding. The horse riding exercise improved the ability of the children with $\mathrm{CP}$ to balance $(\mathrm{p}<0.01)$. The balancing ability of boys was $7.04 \pm 9.96$ in the pre-phase but increased to $33.96 \pm 45.68$ in the mid-phase, and finally increased to $61.63 \pm 94.01$ in the post-phase, indicating an average increase in balance ability of $54.59 \pm 84.05$. Balancing ability in girls increased from $10.17 \pm 5.53$ in the pre-phase, to $24.11 \pm 10.51$ in the mid-phase, to $38.01 \pm 18.20$ in the post-phase, which was an average increase of $27.84 \pm 12.67$ $(\mathrm{p}<0.05)$.

After completing the horse riding program, the children with $\mathrm{CP}$ could stand still on the ground much longer than that before the program. This result indicated that the horse riding exercise had a positive impact on improving balancing ability in children with CP.

Table 3 shows the differences between before and after horse riding based on the type of disability (hemiplegia and paraplegia). In the case of hemiplegia, the participant's disability improved from $11.57 \pm 8.76$ in the pre-phase, to $39.51 \pm 18.31$ in the mid-phase, to $68.74 \pm 42.92$ in the post-phase, which represented an increase to $57.17 \pm 34.16$. In the case of paraplegia, the changes in the children's disability increased from $5.37 \pm 4.69$ in the pre-phase, to $15.49 \pm 12.62$ in the mid-phase, and to $24.76 \pm 24.37$ in the post-phase, indicating an increase to $19.39 \pm 19.68(\mathrm{p}<0.05)$. The hemiplegia group tended to have a slightly greater change than that in the paraplegia group, but no significant difference was observed between the two groups.

\section{DISCUSSION}

This study confirmed the effectiveness of horse riding for improving balancing ability in children with $\mathrm{CP}$. The participants consisted of 13 children with CP however, two girls were excluded from the results. One of the girls did not respond to the study, and the other stopped in the middle of the study due to personal reasons.

The fundamental horse riding posture is to sit straight on the back of the horseand align the points of the head, shoulder, waist, and heel in a vertical line (Lovett et al.,

Table 2. Changes in the rider's balancing ability test scores according to horse riding the experimental period

\begin{tabular}{cccc}
\hline Gender & Pre & Post & $P$ \\
\hline \hline Boys $(\mathrm{n}=5)$ & $7.04 \pm 9.96^{\mathrm{A}}$ & $61.63 \pm 94.01$ & $0.043^{*}$ \\
Girls $(\mathrm{n}=6)$ & $10.17 \pm 5.53$ & $38.01 \pm 18.20$ & $0.028^{*}$ \\
Total $(\mathrm{n}=11)$ & $8.75 \pm 7.59$ & $48.75 \pm 41.06$ & $0.003^{* *}$ \\
\hline
\end{tabular}

Levels of significance: ${ }^{*} p<0.05,{ }^{* *} p<0.001,{ }^{\mathrm{A}}$ means \pm standard deviation

Table 3. Comparison of the rider's balancing ability test scores during the horse riding program according to the type of disability

\begin{tabular}{cccc}
\hline Period & Hemiplegia $(\mathrm{n}=6)$ & Paraplegia $(\mathrm{n}=5)$ & $P$ \\
\hline \hline Pre & $11.57 \pm 8.76^{\mathrm{A}}$ & $5.37 \pm 4.69$ & 0.225 \\
Mid & $39.51 \pm 18.31$ & $15.49 \pm 12.62$ & 0.138 \\
Post & $68.74 \pm 42.92$ & $24.76 \pm 24.37$ & 0.225 \\
\hline
\end{tabular}

Levels of significance: ${ }^{*} p<0.05,{ }^{\mathrm{A}}$ means \pm standard deviation 
2005). The ischium then becomes the axis of the center of gravity. The rider relaxes the upper body and maintains balance to receive and control movements of the horse. In addition, the rider can control the horse easily with an imaginary line that connects the elbows, hands, and the bit (Lovett et al., 2005). Therefore, the rider should ride a horse with an upright posture and acquire the skill to maintain this posture to feel the movement of the horse. During this process, the rider uses global and fine muscles to respond to the movement of the horse and maintain balance. In other words, the rider adapts to the movement of the horse and benefits from the effects of correcting posture by coordinating repeated muscular contractions (Terada et al., 2004).

According to previous studies on horse riding, the various movements of horse riding stimulate posture and equilibrium stabilization by moving the rider's center of gravity (Freeman, 1984; Heiperz, 1981; Spink 1993; Bertoti, 1988). Several studies have used a horse riding program for children with $\mathrm{CP}$ to determine its impact on balance ability. According to those studies, horse riding has a positive impact on improving balancing ability in children with CP (Han et al., 2004; Han, 2011; Ryu, 2011). Han et al. (2004) measured balance ability of children with $\mathrm{CP}$ after a 12 week horse riding exercise program and confirmed that horse riding helps improve balancing ability. Those researchers emphasized that continuous and long duration horse riding is important. Han (2011) conducted a study to determine changes in balancing ability before and after a 16 week horse riding exercise program. According to their results, the participants developed a greater ability to balance after riding a horse than that before the program. They also found that the rate of bilateral symmetry decreased, indicating that the ability to balance increased.

Ryu (2011) carried out a study using Good Balance, to measure the ability of children with $\mathrm{CP}$ to balance. The participants joined an 8 week horse riding program, and the researchers reported the same results as the present study; a horse riding exercise program positively affects balancing ability in children with $\mathrm{CP}$.

Han et al. (2004) also reported that horse riding improves balancing ability, but their results of the sub-category "standing with eyes open" were different from those of the present study. They found no significant change between before and after horse riding. but they conducted their study for only 3 months, and 1 month break was taken from horse riding, whereas we carried out our study for 5 months.
Although horse riding was applied differently in each of the studies, most studies targeting horse riding exercise for children with CP reported positive effects of the therapy and underscored the importance of trotting during horse riding.

Furthermore, in domestic studies, which focused on gross motor function measures to record the level of physical movement for children with CP, Kim et al. (2005) stated that 26 of 29 participants showed an increase of $3.3 \%$ in gross motor function, and most significant increases in $\mathrm{C}$ (crawling and kneeling), D (standing), and E(walking, running, and jumping).

Park and Shin (2010) found that the physical abilities of children with $\mathrm{CP}$, such as A (lying and rolling), B (sitting), and $\mathrm{C}$ (crawling and kneeling) increased after an 8 week horse riding exercise. Additionally, Lee and Lee(2011) compared a group that rode horses with a group that played ball for 12 weeks. According to that study, the horse riding group showed increased physical movement compared to that in the ball group. The horse riding group achieved increased scores in categories, such as B (sitting), $\mathrm{C}$ (crawling and kneeling), and D(standing). As a result of applying horse riding for children with $\mathrm{CP}$, the effects of gross motor function measures were slightly different in each category, but it was generally confirmed that horse riding exercise helped improve physical movement of children with $\mathrm{CP}$, regardless of the specific category.

The present study confirmed that horse riding exercise could be an effective intervention treatment to improve the balancing ability in children with $\mathrm{CP}$. The horse riding program was carried out as a way to boost confidence and motivate the participants by helping them learn to control their horses. We also used trotting with stirrups as a mean to help improve balancing ability.

We aimed to have participants focus on improving their balancing ability using various aids, such as reins and weight, which are tools to communicate with horses. As a result, changes in trotting tempo helped the children learn to absorb the movement of the horse by keeping their balance. Additionally, horse movements such as running, stopping, walking, and trotting, might be a new stimulus for children with $\mathrm{CP}$ who have trouble walking.

In conclusion, a horse riding program helped improve the balancing ability of children with $\mathrm{CP}$. In addition, horse riding exercise is an effective way to strengthen gross motor function, support walking movement, and improve the daily lives of children with $\mathrm{CP}$. 


\section{ACKNOWLEDGEMENT}

We thank the volunteers, participants, and their parents. We also thank Kang Anna, the physical therapist who helped us measure balancing ability.

\section{REFERENCES}

Barlow, J., Cpsychol, Powell, L. and Cheshire, A. 2007. The training and support programme (involving basic message) for parents of children with cerebral palsy; An implementation study. Journal of Bodywork and Movement Therapies, 11(1): 44-53.

Bergene, M. C. 2006. Therapeutic Horse riding in Individuals with Disabilities: Effect on Hip Range of Motion. Senior Research Project, Marian College of Fond du Lac, WI.

Bertoti, D. B. 1988. Effect of therapeutic horse riding on posture in children with cerebral palsy. Physical Therapy, 8:1505-1512.

Dodd, K. J., Taylor, N. J. and Graham, H. K. 2003. A randomized clinical trial of strength training in young people with cerebral palsy. Developmental Medicine and Child Neurology, 45(10):652-657.

Freeman, G. 1984. Therapeutic horse riding. Clin Manage, 4: 20-25.

Han, S. C., Chu, H. G. and Lee, S. H. 2004. The Effects of Horse riding on the Balance Improvement of the Children with Cerebral Palsy, The Korean Journal of Physical Education, 43(2):601-610.

Han, A. R. 2011. Effects of therapeutic horse riding on the gait patterns and equilibrium abilities of the adolescents with brain lesions. Yongin University Graduate School, Master's Thesis.

Heiperz, W. 1981. Therapeutic riding. Medicine, education, sports, Ottawa, Canada, National Printers.

Ionatamishvili, N. I. 2004. Riding Therapy as a Method of Rehabilitation of Children with Cerebral Palsy. Human Physiology, 30:561-565.

Kim, H. S., Lee, K W., Hwang, J. H., Kim, E. J, Lee, Y. T., Chung, S. H., Nam, M. S. and Lee, J. Y. 2005. Therapeutic Effects of Horse riding (Hippotherapy) on Motor Development of Children with Cerebral Palsy, Journal Korea Sports Medicine, 23(3):278-283.

Kwon, J. Y., Chang H. J., Lee J. Y., Ha Y, Lee P. K. and Kim Y. H. 2011. Effects of hippotherapy on gait parameters in children with bilateral spastic cerebral palsy. Archives Physical Medicine Rehabilitation, 92:774-779.

Lee, I. K. and Lee, C. W. 2010. Effects of Horse riding on Gross Motor Functions of Children with Cerebral Palsy, The Journal of Korean Academy of Hippotherapy, 1(1):1-12.

Liptak, G. S. 2005. Complementary and alternative therapies for Cerebral Palsy. Mental Retardation and Developmental Disabilities Research Reviews, 11(2):156-163.

Lovett, L., Hodson-Tole, E. and Nankervis, K. 2005. A preliminary investigation of rider position during walk, trot and canter. Equine and Comparative Exercise Physiology, 2(2):71-76.

Park, G. R. and Shin, J. S. 2011. Rehabilitation of children with cerebral palsy riding effect on improving gross motor function. The Korea Journal of Sports Science, 20(1):775-782.

Ryu, S. W. 2011. The Effects of Hippotherapy on Balance and Upper Extremity. Daegu Haany University Graduate School, Master's Thesis.

Sherri, L., Cadenhead, I. R. and David, M. T. 2002. Effect of passive range of motion exercises on lower extremity goniometric measurements of adults with cerebral palsy: A Single-subject Design. Physical Therapy, 82(7):26-37.

Silkwood-Sherer, D. 2007. Effects of hippotherapy on postural stability, in persons with multiple sclerosis: A pilot study, 31: $77-84$.

Spink, J. 1993. Developmental Riding Therapy: A Team Approach to Assessment and Treatment. Tucson, AZ: Therapy Skill Builders.

Sterba, J. A., Rogers B. T., France A. P. and Vokes D. A. 2002. Horse riding in children with cerebral palsy: effect on gross motor function. Development Medicine Child Neurology, 44: 301-308.

Terada, K., Mullineaux, D. R., Lanovaz, J., Kato, K. and Clayton, H. M. 2004. Electromyographic analysis of the rider's muscles at trot. Equine and Comparative Exercise Physiology, 1(3): 193-198.

Vargus-Adams, J. 2005. Health-Related Quality of Life in Childhood Cerebral Palsy. Archives of Physical Medicine and Rehabilitation, 85(5):940-945.

Yong, H. C., Kim, C. and Hwang, K. Y. 2010. The Effects of Therapeutic Riding on Activities of Daily Living and Gross Motor Functions of Children with Cerebral Palsy, Journal of Rehabilitation Psychology, 17(3):117-131.

(Received May 10, 2012; Revised Jun. 12, 2012; Accepted Jun. 14, 2012) 